\title{
Para uma Estrutura dos Provérbios nas Línguas Românicas: uma Experiência
}

\author{
Maria Lucia Mexias-Simon \\ Universidade Severino Sombra, Revisão das Revistas Eletrônicas \\ da USS, Editoria da Revista Mosaico - Revista Multidisciplinar \\ de Humanidades e Coordenadoria de Pesquisa \\ mmexiassimon@yahoo.com.br
}

\begin{abstract}
Resumo: Sendo a língua dinâmica e mutante, os provérbios permanecem em sua forma arcaizada que lhes dá o aval da tradição. Encontram-se semelhanças fônicas. morfo-sintáticas e lexicais entre as frases feitas em diversas linguas. São os provérbios ainda semelhantes quanto à preferência por determinadas esferas semânticas e quanto a seu emprego na manutenção do estabelecido.
\end{abstract}

Palavras-chave: Análise do discurso. Frases feitas. Folclore

\section{Pour une Structure des Proverbes Dans Les Langues Romaniques: une Experience}

\begin{abstract}
Resumé: La langue étant dynamique et changeable, les proverbes restent en leur forme archaisée, qui leur donne l'aval de tradition. On trouve des ressemblances phonétiques, morpho-syntatiques el lexicales entre les phrases faites en plusieurs langues. Les proverbes sont, en outre, semblables pour determinés secteurs sémantiques et quant à leur emploi dans la manutention de l'établi.
\end{abstract}

Mots-clé: Analyse du discours. Phrases faites. Folk-lore.

Os chamados ditos populares existem em quase todas as línguas naturais. Isso pode ser comprovado pela existência de inúmeras de suas coletâneas, em distantes idiomas, no tempo e no espaço. Alguns povos são notoriamente mais produtivos nesse setor, como por exemplo, os chineses. Os filólogos encontram na fraseologia popular elementos de estudo. Em forma concisa, de sonoridade agradável, ela guarda sobrevivências históricas, idiomáticas e sociais. Permite-nos acompanhar a história da humanidade e de cada povo. São as maneiras de falar "uma expressão constituída pela união de várias palavras, formando uma unidade sintática e lexicológica. ${ }^{1}$ Distinguem-se das locuções prepositivas e conjuntivas; formando torneios idiomatológicos; estão à margem do uso normal da língua por suas características de forma e de som, pelo afastamento das normas lexicais e gramaticais e por seus valores metafóricos particulares, como se verá no decorrer do 
presente trabalho.

São signos arbitrários, porque a imagem que está na sua origem tende a se obscurecer, como de resto, em todos os signos linguísticos.

$\mathrm{Na}$ tentativa de análise da motivação inicial, a locução é rebelde, na maioria dos casos, a qualquer estudo histórico. A língua é sem dúvida o espelho do povo. Mas, se formos procurar atrás de cada palavra uma causa externa e material pode-se acabar por falsear os fatos A língua é um produto da história, do meio, as causas históricas de origem dos fatos linguísticos são numerosas, porém, uma minoria de fatos, baseados na forma própria, da língua, são os mais característicos e, portanto, os mais interessantes do ponto de vista linguístico. Isso se ajusta às locuções estereotipadas. É, por conseguinte, difícil e perigoso procurar saber a etimologia das frases que retemos de memória e aplicamos em diversas circunstâncias:

- Amor com amor se paga

- Devagar se vai ao longe

- Petit à petit, 1'oiseau fait son nid

Inclusive a fraseologia registrada em obras literárias ou religiosas não nos tira a dúvida, se tais expressões foram recolhidas e registradas pelos autores e compiladores dessas obras, ou se o povo as adota porque viu nelas aplicações para a vida prática. O seu aspecto arcaizado, na construção e no léxico, constitui exatamente o seu aval. O povo acredita nelas, pois são assim repetidas há várias gerações. Não importa que assentem em bases falsas:

- Martes, ni te cases, ni te embarques

- En martes, ni tela urdas, ni hija cases

O conceito de martes como dia aziago viria da derrota sofrida por valencianos e aragoneses nos campos de Luxón em 1276. ou de ser o dia consagrado ao deus da guerra?

Também a moral das fábulas pode ter sido adotada como dito popular, como podem ser as fábulas paráfrases de ditos já existentes.

A origem mais remota da fraseologia popular encontra-se nos velhos berços da civilização, na China tradicional, no Egito. na Índia e na Pérsia, até a civilização greco-romana, na Bíblia, nas subsequentes obras inspiradas pelo Cristianismo, sobretudo no livro conhecido como Imitação de $\underline{\text { Cristo. }}$

Já em Protágoras, afirma Platão; "a maneira dos antigos sábios era caracterizada por uma espécie de concisão lacônica...sentenças concisas e dignas de memória... máximas que estão em todas as bocas". ${ }^{2}$

Como o folclore universal remonta sempre às mais recuadas fontes do passado, vai (a fraseologia popular - parênteses nossos) prender-se em última análise, geralmente à letra dos livros sagrados. Não raro, a fábula ou o conto, cuja manifestação moderna nos 
parece original, emigrou de papiros egípcios... nasceu no Zend-Avesta.. veio dos Puranas ou dos VedasTanto quanto esses livros santos, a Bíblia não podia deixar de ser também fonte abundante de folclore quer repetindo temas já citados em outros repositórios, quer dando em primeira mão fatos novos e quer sendo origem de dizeres modificados ao saber popular. $^{3}$

O uso das locuções extraídas das obras literárias e dos livros religiosos é variável segundo o meio, o grau de instrução, os hábitos individuais. O latim medieval foi o meio de transmissão dessa herança antiga Nos romances, os ditos populares aumentam em número de variantes, com tendência a diminuir em tamanho. Alguns conservaram-se em latim:

- Sic transit gloria mundi

- In vino ventas

Na Idade Média já quase não se criaram expressões populares, mas conservaramse e transmitiram-se "entre os que iam e vinham da feira e os que faziam paradas em pousadas e hospedarias" " No autoritarismo e no conservadorismo da Idade Média, encontraram os ditos dos mais autorizados pela idade e pela cultura terreno favorável à sua permanência.

Excetuam-se do caráter de dito popular as frases que foram a propósito forjadas para serem gravadas e lidas pelos educandos ou para exteriorização de sentimentos:

- Nem cora o livro de ombrear com o sabre, nem cora o sabre de chamá-lo- irmão. ${ }^{5}$

N'insultez jamais une femme qui tombe. ${ }^{6}$

Excetuam-se também aquelas que, verdadeiramente ou não, foram proferidas por personagens de destaque em circunstâncias históricas:

- Vim. vi, venci.

- Tudo como dantes, no quartel-general d 'Abrantes.

- L'état'est moi!

Não serão aqui tratadas, também, as frases, embora do domínio popular, constantes em livros sagrados, pois estas tem seu espaço próprio e também por falta de edições confiáveis.

A utilização dos ditos populares na literatura é prática usual, desde a Antiguidade, sendo muito mais frequente na literatura dramática. Encontram-se em Gil Vicente, Camões. Shakespeare; Alfredo Cunha baseia-se em pesquisa de estudiosos para garantir-nos que nas peças Eufrosina e Ulyssipo de Jorge Ferreira de Vasconcellos encontram-se respectivamente mais de 600 e mais de $500 \underline{\text { ditos }^{7}}{ }^{7}$. (grifo nosso).

A esse respeito, encontramos na Dissertação de Flora de Paoli Faria sobre Gtovani Verga:

A leitura dos textos enfatiza a importância da cultura popular como manancial ao qual se deve recorrer na busca de motivos autênticos, 
originais... Muitas são as definições atribuídas ao termo 'folclore'. Dentre elas, por exemplo, a possibilidade de reconhecer o folclore como a expressão exclusiva das classes mais humildes. Ela se opõe ao parecer de pesquisadores alemães que afirmam ser o folclore pertinente a iodas as classes sociais... Os conflitos inerentes à conceituação do âmbito folclórico se extinguem, quando entendemos que todos os aspectos do folclore são expressões de uma única força produtora, assinalada peia coletividade humana em seu continuo movimento de conservação e desenvolvimento... O estudo do conjunto folclórico permite a percepção de vários ritos usados pelo homem para orientar-se em sua caminhada em busca do conhecimento... A utilização de provérbios é uma constante... na produção de Verga não sendo utilizado unicamente como uma curiosidade folclórica ou dialetal. Os provérbios servem para destacar o peso da tradição popular no contexto regional. ${ }^{8}$

O que aqui se atribui a Giovani Verga, pode-se dizer da literatura em geral. O emprego da fraseologia estereotipada na literatura caracteriza um personagem, uma coletividade, uma região. Se bem que se encontram fórmulas de âmbito quase universal, surpreendentemente. O popular -- Time is money - que tanto nos parece caracterizar o moderno pragmatismo norte-americano, encontra equivalente na coletânea do Pe. António Delicado, em 1651 Perdendo tempo não se ganha dinheiro. ${ }^{9}$

Johan Huizinga estabelece "estreita interligação cultural entre palavras como conselho, enigma, mito, lenda, provérbio, etc.” Vejam-se as relações etimológicas entre os termos:

\begin{tabular}{|c|c|c|}
\hline$\underline{\text { Alemão }}$ & $\underline{\text { Holandês }}$ & $\underline{\text { Português }}$ \\
\hline Rätsel & Raadsel & Enigma \\
\hline Rat & Raad & Conselho \\
\hline erraten & --- & adivinhar \\
\hline raten & raden & aconselhar, adivinhar \\
\hline
\end{tabular}

"Também em grego existem afinidades entre aívos (sentença, provérbios) e aíıvı $\mu \alpha$ (enigma) Podemos concluir que originariamente o enigma era um jogo sagrado, e por isso se encontrava para além de toda distinção possível entre o Jogo e a seriedade Clearco, um dos discípulos de Aristóleles, escreveu um tratado sobre os provérbios, o qual encerrava uma teoria dos enigmas, provando que, originariamente, o enigma fora um assunto filosófico... A própria palavra problema, 'aquilo que é colocado diante de alguém' aponta para o desafio como origem da proposição filosófica... o filósofo... assumiu todas as características de um campeão."10

Os termos provérbio, problema, profecia, pertencem ao campo do jogo social, sendo o provérbio a regra desse jogo. Huizinga ainda inclui no jogo a figura do vates, originariamente, o possesso, inspirado por Deus, em transe e, mais tarde, 
O poeta-vidente (que) vai gradualmente assumindo as figuras do profeta, do sacerdote, do adivinho... e do profeta tal como o conhecemos. O eterno abismo entre o ser e a ideia só pode ser franqueado pelo arcoíris da imaginação: Os conceitos, prisioneiros das palavras, são sempre inadequados em relação à torrente da vida; portanto, é apenas a palavraimagem, a palavra figurativa que é capaz de dar expressão às coisas e. ao mesmo tempo, banhá-las com a luminosidade das idéias; ideia e coisa são unidas na imagem... Elementos como rima e o dístico só adquirem sentido dentro das estruturas... de que derivam: golpe e contragolpe, ascensão e queda, pergunta e resposta, numa palavra, ritmo. ${ }^{11}$

Ai estaria a raíz dos provérbios, objeto do presente estudo

Inicialmente, trataremos da dificuldade em batizar a locução estereotipada que faz parte do repertório léxico de um povo, ou de vários povos, face ao grande número de denominações.

A seguir traçaremos breve histórico das coletâneas de expressões populares mais famosas. Prosseguindo, descreveremos tais expressões em suas estruturas fônica, morfo-sintática e lexical Assinalaremos os campos semânticos mais abordados em tais locuções. Aqui, usaremos um corpus colhido entre alunos do 2 grau de um colégio estadual. Na última parte, abordaremos o provérbio como discurso catequético (o discurso do dever/fazer). Utilizaremos, como apoio, uma peça do teatro brasileiro, abundante em citação de provérbios, A partir dos exemplos ai coletados, mostraremos como as locuções populares legislam nos diversos aspectos vida humana. Aqui deixaremos em aberto a questão: Provérbios são feitos pelo povo ou para o povo? Partem das massas, destinam-se a elas e à juventude, isto é, aqueles que devem ser doutrinados?

E de se registrar uma grande deficiência para esse estudo, que é a quase inexistência de material autêntico de coleta de provérbios na linguagem falada Nesse setor. temos conhecimento apenas de um estudo realizado por K Daniels na Escola Superior de Pedagogia de Bonn; ${ }^{12}$ comprovou-se que as crianças (a idade não é mencionada) identificam de imediato os provérbios como tais; sabem que esses são empregados na comunicação, quando o falante quer dar validade à sua argumentação, não são verdadeiros em si, até porque os há contraditórios e porque o mundo mudou profundamente.

- Mais vale um pássaro na mão que dois a voar

- Quem não arrisca não petisca

- Gordura é formosura

A experiência teve como objetivo fazer com que os alunos se distanciem da autoridade do provérbio e reconheçam que esses são usados num determinado contexto, com um determinado objetivo. Porém, aqui se trabalhou com material recolhido com finalidade didática especifica.

No Brasil, realizou-se experiência, em 1977, por alunos da 5a série da Escola Alencastro Guimarães, no Rio de Janeiro. Os alunos solicitaram a pessoas que estavam em uma feira, 
que lhes dessem exemplos de provérbios. Os informantes são, em maioria, mulheres nordestinas, com primário completo. Alguns exemplos colhidos:

- Águas passadas não movem engenho

- Cré com cré e Cupumãm (sic) com chaminé

- Quem muitas pedras bole, uma lhe dá na cabeça

- Pra baixo todo santo ajuda, pra cima a coisa toda muda

Você vai ver com quantos paus se faz uma cangalha. ${ }^{13}$,

As frases apresentadas no presente trabalho foram extraídas das coletâneas citadas na bibliografia e, algumas, da observação pessoal. Por ser um trabalho de Filologia Românica, consideramos as três línguas românicas com maior número de falantes: português, francês e espanhol (a sequência não corresponde ao número de falantes), mostrando que as características a serem assinaladas encontram-se frequentemente, em provérbios examinados nessas três línguas- Por razões óbvias, é em português apresentado o maior número de exemplos.

Concordamos com Algirdas Julien Greimas ${ }^{14}$ que o conjunto de provérbios e ditados em dado tempo e lugar constitui um sistema de significação fechado com estatuto formal autônomo que leva a postular, por hipótese, a existência de um domínio semântico independente. O seu estudo explicaria alguns problemas de estilística e contribuiria para o estudo do simbolismo coletivo: mitos, sonhos, folclore.

Num primeiro levantamento dos campos semânticos frequentes em provérbios usados na nossa comunidade- nos dias de hoje, realizamos pesquisa junto a alunos do Colégio Estadual Raul Fernandes. na cidade de Vassouras, nos dias 22 e 23 de setembro de 1988. Foram escolhidas uma turma do 3 ano de formação de professores, do $1^{\circ}$. turno, com faixa etária mais baixa e, em quase totalidade, do sexo feminino e uma turma do 3 ano técnico em contabilidade do $3^{\circ}$ turno, com faixa etária mais elevada e, em quase totalidade, do sexo masculino. Procurou-se, assim, diversificar a amostragem, ainda que em escala pequena,

\begin{tabular}{|c|c|c|}
\hline \multicolumn{3}{|c|}{$\underline{\text { Idade }}$} \\
\hline 15 anos - 11 & 19 anos & 6 \\
\hline 16 anos - 6 & 22 anos & I \\
\hline 17 anos - 7 & 23 anos & I \\
\hline 18 anos -7 & 32 anos & I \\
\hline
\end{tabular}

\begin{tabular}{|ll|}
\hline \multicolumn{2}{|l|}{ Grau de instrução do pai e da mãe } \\
\hline Analfabeto & 4 \\
$1^{\circ}$ grau incompleto & 25 \\
$1^{\circ}$ grau completo & 19 \\
$2^{\circ}$ grau & 15 \\
$3^{\circ}$ grau & 7 \\
Não declarado & 10 \\
\hline
\end{tabular}


No conjunto, foram entrevistados 40 alunos distribuídos nos seguintes padrões:

Foi solicitado aos informantes declarar por escrito o maior número possível de provérbios de que conseguissem se recordar, depois de indagar se eles sabiam o que é um provérbio e de receber alguns exemplos oralmente, que foram depois também levados em consideração. Foi ainda solicitado que os informantes declarassem onde e por qual pessoa o provérbio citado é mais frequentemente utilizado, sendo a resposta, em $90 \%$ dos casos, em casa, com parentes ou amigos da família.

Nas respostas colhidas observaram-se algumas frases que mais se aproximam do discurso literário propriamente dito ( a maior arma do homem é a dignidade; o trabalho engrandece o homem ); outras no estilo parachoque de caminhão (mulher no volante, perigo constante; feliz foi Adão que não teve sogra); outras recolhidas em programas de televisão (Jovem é outro papo); e até mesmo slogans de campanhas comunitárias (violência não; liberdade com responsabilidade).

Abstraindo os enunciados nos tipos mencionados, mais as referências bíblicas e as frases de formulação recente, que não podem ser enquadradas como provérbios, exatamente por lhes faltar a característica de antiguidade (quem não cola, não sai da escola), chegamos a um corpus formado por 76 provérbios; consideram-se como provérbios, enunciados, conotativos ou não, do conhecimento da maioria dos informantes e que expressam uma fórmula de bom comportamento ou de descrição do universo e seus valores.

A seguir, foi feita a classificação desses provérbios, de acordo com a divisão de Walter Gottschalk. havendo como era de se esperar, muitos capítulos que não foram preenchidos, assim como alguns provérbios à parte da mencionada. Alguns itens foram reunidos em um só, por afinidade.

Fica o Corpus assim constituído, levando-se em conta o campo semântico dos lexemas que nele aparecem, alguns provérbios serão aqui mencionados mais de uma vez, a fim de melhor observação da incidência dos campos semânticos:

1. a natureza:

a) inorgânica:

- água fria (sic) em pedra dura tanto bate até que fura (citado 17 vezes)

- depois da tempestade vem a bonança (citado 10 vezes)

- (não) fazer tempestade em copo d'água (citado 2 vezes)

- quem brinca com fogo, se queima (citado 2 vezes)

- quem chega na frente, bebe água limpa

- quem com ferro fere, com ferro será fendo (citado 16 vezes)

b) vegetal:

- fruta não cai longe da árvore 
Dossiê Temático:

Memória como Fonte de Pesquisa

- pau que nasce torto até a raiz é torta

- quem planta colhe

- (não) cutucar onça com vara curta

- quem se mistura com porcos, farelos come (citado 2 vezes)

- cada macaco no seu galho (citado 3 vezes)

- de grão em grão, a galinha enche o papo (citado 6 vezes)

- enquanto você vai com o milho, eu volto com o fubá (citado 2 vezes)

- em mulher não se bate nem com uma flor

c) animal:

- a cavalo dado não se olham os dentes

- em boca fechada não entra mosca

- cobra que não anda, não engole sapo

- cada macaco no seu galho (citado 2 vezes)

- mais vale um pássaro na mão que dois voando (citado 26 vezes, inclusive as variantes)

- (não) por a carroça na frente dos burros

- (não) cutucar onça com vara curta

- quem guarda com fome, o gato vem e come

- quando o gato sai de casa, o rato faz a festa

- quem não tem cão, caça com gato

- quem se mistura com porcos, farelos come

- quando o burro fala, o outro abaixa a orelha

- de grão em grão, a galinha enche o papo

- uma andorinha não faz verão (citado 2 vezes)

- o castigo vem a cavalo

2. o ser humano e seu corpo:

- a mentira tem pernas curtas (citado 2 vezes)

- quem tem um olho no país de cego é Rei (sic)

- quem vê o corpo não vê o coração (sic)

- quem tem boca vai a Roma (citado 3 vezes)

- em boca fechada não entra mosca

- há sempre um chinelo velho para um pé cansado

Mosaico - Revista Multidisciplinar de Humanidades, Vassouras, v. 2, n. 2, p. 59-74, jul./dez., 2011 
- amigos só os dentes e ainda mordem a língua da gente

- pimenta nos olhos dos outros é refresco

3. a vestimenta do ser humano:

- há sempre um chinelo velho para um pé cansado

4. a alimentação do ser humano:

- pimenta nos olhos dos outros é refresco (citado 3 vezes com variantes)

- quem tem pressa, come cru (citado 2 vezes)

- quem chega na frente, bebe água limpa

- quem guarda com fome, o gato vem e come

- quem se mistura com porcos, farelos come

- farinha pouca, meu pirão primeiro

- enquanto você vai com o milho, eu volto com o fubá

5. a moradia do ser humano e sua instalação;

- $\quad$ saco vazio não para em pé (citado 10 vezes)

- preto quando não suja na entrada- suja na saída (citado 11 vezes)

- sempre que Deus fecha uma porta, abre uma janela

- (não) fazer tempestade em copo d'água

- não adianta dar soco em ponta de faca

- (não) por a carroça na frente dos burros

6. as profissões, a caça, os jogos, os esportes:

- um dia é da caça, outro do caçador (citado com variantes)

- quem não tem cão, caça com gato

- branco quando corre é atleta, preto quando corre é ladrão

- quem brinca com fogo, se queima

7. a guerra (combate):

- quem com ferro fere, com ferro será ferido

8. moeda e valores:

- de milhão em milhão, se chega ao quadrilhão 
Dossiê Temático:

Memória como Fonte de Pesquisa

9. a contagem de tempo e as festas:

- depois de cada noite, há sempre um amanhecer

- nada melhor que um dia depois do outro (citado 4 vezes com variantes)

- amanhã será um novo dia

- um dia é da caça, outro do caçador

- não deixe para amanhã, o que pode fazer hoje (citado 2 vezes)

- o mundo dá muitas voltas

- uma andorinha não faz verão

10. a família, a vida em família, os acontecimentos familiares:

- o que a mulher quer, Deus quer (citado 5 vezes)

- mulher de amigo meu pra mim é homem

- em briga de marido e mulher, ninguém mete a colher

11. as cidades, os países, os povos:

- quem tem boca vai a Roma (citado 3 vezes)

- branco quando corre é atleta, preto quando corre é ladrão

- preto quando não suja na entrada, suja na saída

12. o governo e a situação:

- quem tem um olho no pais de cego é Rei

13. Deus a Igreja e seus ritos:

- Deus escreve certo por linhas tortas (4 vezes)

- o que a mulher quer, Deus quer

- sempre que Deus fecha uma porta, abre uma janela

- Deus ajuda a quem cedo madruga (citado 3 vezes)

- devagar com o andor, que o santo é de barro (citado 2 vezes)

- santo muito recomendado não vai para o céu

- quem não morre, não vê Deus

14. língua e gramática:

- Deus escreve certo por linhas tortas 
15. sem classificação:

- aqui se faz. aqui se paga (citado 8 vezes, com variantes)

- a esperança é a última que morre (citado 3 vezes)

- seguro morreu de velho

- tudo que sobe, desce

- quem pode, pode, quem não pode, se sacode (citado 2 vezes)

- (o bom) é para quem pode, não para quem quer (citado 2 vezes, com variantes)

- quem ri por último, ri melhor (citado 3 vezes)

- ladrão que rouba ladrão, tem cem anos de perdão

- um homem prevenido vale por dois

- antes só que mal acompanhado (citado 2 vezes)

- antes tarde do que nunca

- ruim seria, se pior fosse

- querer é poder

- errar é humano

- amigos, amigos, negócios à parte

- depois do tombo, se aprende a levantar

- quem espera, sempre alcança (citado 4 vezes com variantes)

Devem-se fazer as seguintes observações:

- a classificação foi feita pela denotação do lexema que neles aparecem, muito embora as dificuldades de análise linguística de que já falamos.

- a redação foi normatizada pelas regras gramaticais vigentes, mantendo-se o vocabulário, mesmo quando inusitado, não se apresentam aqui, os paralelos nos outros idiomas observados (francês e espanhol), por, frequentemente, a tradução de um provérbio ser feita mantendo-se a ideia no seu todo, porém com lexemas diferentes, o número de citações refere-se à frequência com que o provérbio foi informado.

No exame do corpus podemos apresentar conclusões, por exemplo:

- é alta a incidência de provérbios formulados a partir da observação da natureza;

- o setor mais produtivo é o que se refere aos animais domésticos, considerando-se animais domésticos aqueles que vivem dentro do território de propriedade do homem e de cujos produtos ou serviços o homem se utiliza, dos animais domésticos, o mais citado é o gato - animal sagrado no Egito, foi levado para a Europa na Idade Média, 
a fim de acabar com os ralos - a ele se atribuem as ações de autoria desconhecida, as ações que normalmente não lhe são próprias;

- das atividades humanas que se podem dizer profissionais a caça é a mais citada - era muito prestigiada durante a Idade Média, tida como atividade exclusiva dos nobres;

- a presença de ditos pejorativos sobre a raça negra é curiosa, dado que os informantes são $70 \%$ negros ou mulatos - dado cultural assimilado, automaticamente repetido- ou uma agressão às avessas, nascer negro, nascer mulher são problemas - o signo corporal reflete-se na linguagem;

- em relação à vida em família. todos os ditos envolvem a mulher - ela pertence ao homem, faz parte do seu patrimônio de uma forma ou de outra adquirido, mas é, ao mesmo tempo, por ele respeitada, como mais próxima dos poderes sobrenaturais que o homem;

- de Deus provêm todos os benefícios e só benefícios - nenhuma dúvida quanto aos seus infinitos poderes e misericórdia; a mesma segurança não existe em relação aos seus santos que seriam frágeis e falíveis.

Como pudemos verificar, na presente dissertação, o estudo dos ditos populares leva-nos, na sua história e na sua descrição, à consideração de diversos aspectos, Primeiramente, deparamo-nos com o grande número de denominações para tais ditos: provérbios, ditados, anexins. refrães, etc. Consultando coletâneas, dicionários, além de obras sobre o assunto, mostramos como os autores estabelecem definições para alguns desses termos, assim como traçam critérios de distinção entre uns e outros. Mostramos, a seguir, como tal estudo sempre despertou interesse, mencionando algumas das coletâneas mais estudadas - por sua antiguidade, ou por alguma curiosidade de forma como de conteúdo - no Brasil, em Portugal, na França e na Espanha. De coletâneas publicadas em francês e em espanhol ultramarinos, não se encontrou notícia.

$\mathrm{Na}$ análise do significante do provérbio destacamos as afinidades fônicas, morfo-sintáticas e lexicais existentes entre as locuções empregadas por povos de línguas diferentes.A linha melódica dos provérbios apoia-se, quase sem exceção, em uma estrutura binária, reforçada pelo ritmo e peia rima, o que faz um provérbio, não um enunciado, mas dois enunciados, como afirmam alguns autores. Também quanto aos aspectos morfo-sintático e lexical,observamos pontos em comum nos idiomas estudados tais como: uso frequente de orações adjetivas determinativas, emprego do verbo na $3^{\text {a }}$. pessoa, introduzido por dêticos, formação verbal, construção frasal e vocabulário arcaizados; uso de topônimos e antropônimos que não podem ser justificados a não ser que se recorra a incidentes históricos. A paremiologia é um repositório de arcaísmos, como é também conservador o provérbio no seu conselho, sendo sua antiguidade o que o ratifica. Nesse particular, o aspecto tônico é determinante da escolha de uma ou outra construção, de um ou outro vocábulo, tornando o provérbio sonoro, conciso, de fácil memorização. Chegou-se a essa conclusão pela leitura de várias antologias, com o registro das características mais frequentes na fraseologia popular nelas constante e também, por vezes, em exemplos colhidos por observação pessoal direta. Para se conhecer os campos semânticos mais 
frequentes nos provérbios empregados atualmente, levantou-se um corpus, que foi normatizado de acordo com o valor denotativo dos lexemas que neles aparecem. No tratamento do provérbio como discurso de dominação partiu-se da leitura de uma peça teatral contemporânea para chegar ao ponto em que se encontram a descrição linguística e cientifica do provérbio e a didática da língua. Devem-se considerar as estratégias do falante ao empregar um provérbio em seu discurso. Do conhecimento crítico dos estereótipos tende-se a, por ironia ou rebeldia, desmontar os provérbios, parodiando-os Esse fato também se registra nos três idiomas considerados, como também se registram as outras características mencionadas. Se se encontra a mesma expressão em diversas línguas, esse paralelismo de pensamento pode ser explicado pela semelhança de constituição psíquica entre povos migrantes. Ou se trata de uma poligênese?

\begin{abstract}
A maior parte das locuções figuradas viajam. Elas saltam as fronteiras linguísticas com uma facilidade bem maior que os simples fatos materiais do vocabulário A fraseologia europeia está cheia de calques, que se encontram ao lado das criações autóctones Trata-se de um helenismo tomado um pan- europeismo ...? Ou ... poder-se-ia chamar uma poligênese, quer dizer, uma criação espontânea capaz de ser repetida na própria Europa, tantas vezes quantas aí se produziu um centro de civilização e literatura. ${ }^{15}$
\end{abstract}

Para esclarecer a semelhança de expressões estereotipadas de uma língua a outra, deve-se considerar, também, o fato de provirem essas, em grande numero, dos livros sagrados e das antigas obras de filosofia e de literatura, tendo-se perdido em muitos casos, a sua origem e o caminho percorrido, Quer se trate de criações autóctones, sincrônicas- em povos com culturas afins, quer se trate de contágio, tenha havido ou não intenções literárias e/ou didáticas em seu nascedouro, são, atualmente, os provérbios, patrimônio dos povos que os usam. São, portanto, o mais límpido espelho da linguagem popular e dos conhecimentos inculcados, em relação à natureza e à sociedade, representam um manual de pragmática sabedoria de vida, enquanto liberam um olhar no mais profundo dos pensamentos e dos sentimentos. 
Dossiê Temático:

Memória como Fonte de Pesquisa

\section{Notas}

1. GUIRAUD, P. 1962, p. 05.

2. PLATÃO. Oeuvres.Traduction nouvelle des notices et des notes para E. Chambry. Paris: Garnier, 1922 (A tradução do francês é nossa).

3. BARROSO, G, 1960. p 83.

4. CORSO, F 1942,p IX

5. CASTROALVES, A. “Quem dá aos pobres empresta a Deus”. Verso 13-14. In: MAGALHÃES Jr. 1977, p.5.

6. VICTOR HUGO, Chants du crépuscule, In: idem, p. 207.

7. CUNHA, A . C. (1929) p. XIV.

8. FARIA, F. P. (1983) p. 68-74.

9. BATALHA, L. (1924) p. 233-234.

10. HUIZINGA, J. (1980) p. 125-130.

11. Op. cit. p. 125-157.

12. SCHMIDT-RADEFELDT, J. (1984) p. 233-234.

13. BARRETO, M.L.B. (1979) p. 288-295

14. GREIMAS, A . J. (1975) p 288-295.

15. KLEIN, H.W. 1936, p 08.

\section{Referências}

Barreto, Mônica L. de Barros. (1979) (org) Do jeito mais simples. Rio de Janeiro, FUNARTE/SEC, 2v.

Barroso, Gustavo. /s.d./ Através dos folclores. São Paulo, Melhoramentos; Rio de Janeiro, Cayeiras $196 \mathrm{p}$.

Corso, Felix F. (1942) Refranero espanol. Buenos Aires, Libreria Perlado, 292 p.

Cunha. Alfredo Carneiro da. (1929) Ditames e ditérios; glosas em verso de ditados ou dizeres comuns. Lisboa, Empresa Nacional de Publicidade. 3v.

Cunha. António Geraldo da. (1982) Dicionário etimológico da língua portuguesa. Rio de Janeiro, Nova Fronteira, 839 p.

Faria, Flora de Paoli. (1983) A estruturação do regionalismo em Giovanni Verga, dissertação de Mestrado em Teoria Literária, na UFRJ, fl.68-69 e fl.74.

Gottschalk, Walter. (1935-1938) Die bildhaften Sprichwörter der Romanen. Heideiberg, Carl-Winters Universitätsbuchhandlung, $3 \mathrm{v}$.

Greimas. Algirdas Julien. (1960) Idiotismes, proverbes et dictons. Cahiers de lexicologie. Paris, Didier Larousse (v.2) p. 41-62. 
(1975) Os provérbios e os ditados. Sobre o sentido - ensaios semióticos Tradução de Ana Cristina Cruz e outros, Petrópolis. Vozes, p. 288-295.

Guiraud, Pierre. (1962) Les locutions françaises. Paris, Presses Universitaires de France, $122 \mathrm{p}$.

Huizinga. Johan. (1980) Homo ludens, 2. ed. São Paulo, Perspectiva, 242 p.-

Klein, Hans Wilhelm. (1936) Die volkstümlichen sprichwõrtlichen Vergleiche im Lateinischen und in den romanischen Sprachen. Un. Tübingen, 98 p.-

Könnig, Werner. (1985) Atlas zur deutschen Sprache. 6. ed. München. DTV, 250 p.

Magalhães JR. Raimundo. (1977) Dicionário brasileiro de provérbios, locuções e ditos curiosos. Rio de Janeiro, Documentário, 330 p.

Mello, Fernando Ribeiro de. (1974) Nova recolha de provérbios e outros lugares comuns portugueses. Lisboa, Afrodite, 385 p.

Mota, Leonardo. (1982) Adagiário brasileiro, Fortaleza, Edições Universidade Federal do Ceará; Rio de Janeiro, J. OIympio, 433 p.

Nascentes, Antenor. (1936) Tesouro da fraseologia brasileira. 3.ed. rev. por Olavo Aníbal Nascentes. Rio de Janeiro, Nova Fronteira, 431 p.

Pineaux. J. (1963) Proverbes et dictons français. Paris. Presses Universitaires de France. $128 \mathrm{p}$.

Ribeiro, João. (1960) Frases feitas. 2. ed. org. por Joaquim Ribeiro. Rio de Janeiro, Francisco Alves, 432 p.

Schmidt-Radefeldt, Jürgen. (1984) Descrição semântica e funções semanfóricas do provérbio. Estudos de linguística portuguesa. Coimbra Editora, p. 213-235.

Silva, Helena Maria Quintão Duarte e QUINTAO, José Luís. (1983) Pequeno dicionário de provérbios, Lisboa Editores, $163 \mathrm{p}$.

Steinberg, Martha. (1985) 1001 provérbios em contraste. São Paulo. Ática, 127 p. 